\title{
O MOVIMENTO DE REPRODUÇÃO SOCIAL E RESISTÊNCIA NA CONSTRUÇÃO IDENTITÁRIA DE UMA PESSOA TRANS NUMA ATIVIDADE DE LÍNGUA INGLESA À LUZ DOS CONCEITOS DE INDEXICALIDADE E ESCALA
}

\section{THE MOVEMENT OF SOCIAL REPRODUCTION AND RESISTANCE IN THE IDENTITY CONSTRUCTION OF A TRANS PERSON IN AN ENGLISH LANGUAGE ACTIVITY IN THE LIGHT OF THE CONCEPTS OF INDEXICALITY AND SCALE}

\section{Luiz Martins de Lima Neto ${ }^{*}{ }^{* *}$}

\section{RESUMO}

Neste artigo, rediscuto, à luz dos conceitos de indexicalidade e escala, o movimento de reprodução social e resistência numa atividade de língua inglesa, na qual as/os alunas/os de um curso de inglês e eu, professor da turma, construímos a identidade de uma pessoa trans (BENTO, 2014). Tal movimento foi primeiramente discutido na minha dissertação de Mestrado (LIMA-NETO, 2017). A rediscussão do material empírico neste texto mostra que os conceitos utilizados contribuem para a compreensão de como as ideias e os comportamentos hegemônicos são reproduzidos e resistidos interacionalmente, principalmente, porque nos permitem relacionar o micro ao macro, e vice-versa, mostrandonos, assim, como esses dois níveis escalares se constituem, de fato, mútua e indexicalmente. Palavras-chave: reprodução social; resistência; construção identitária, indexicalidade; escala.

\section{ABSTRACT}

In this article, I rediscuss, in the light of the concepts of indexicality and scale, the movement of social reproduction and resistance in an English language activity, in which the students of an English course and I, the teacher of the group, have constructed the identity of a trans person (BENTO, 2014). Such movement was first discussed in my master's dissertation (LIMA-NETO, 2017). The rediscussion of the empirical material in this text shows that the concepts utilised contribute to the understanding of how hegemonic ideas and behaviours

\footnotetext{
* Programa de Pós-Graduação em Letras e Linguística da Universidade Federal de Goiás, UFG Goiânia, GO, Brasil

** Rede Municipal de Educação, RME, Goiânia, GO, Brasil.lmln2509@gmail

Orcid: https://orcid.org/0000-0003-4500-9415
} 
are interactionally reproduced and resisted, mainly because they allow us to relate the micro to the macro, and vice-versa, thus showing us how these two scalar levels, really, constitute each other in a mutual and indexical way.

Keywords: social reproduction; resistance; identity construction; indexicality, scale.

\section{INTRODUÇÃO}

Neste artigo, rediscuto, à luz dos conceitos de indexicalidade e escala, o movimento de reprodução social e resistência numa atividade de língua inglesa, na qual as/os alunas/os de um curso de inglês e eu, professor da turma, construímos a identidade de uma pessoa trans (BENTO, 2014), tendo como base o seu corpo, e sendo trans um termo guarda-chuva que utilizo no trabalho para me referir às/ aos travestis, às/aos intersexuais, às/aos transgêneras/os, às pessoas queer (LIMANETO, 2017, p. 68, grifo no original) etc. Embora Megg Rayara Gomes de Oliveira $^{1}$ (em conversa com Silva, 2020), primeira Doutora travesti negra do País, se posicione radicalmente contra a utilização de termos genéricos como esse para nos referirmos a subjetividades e especificidades identitárias tão distintas umas das outras, principalmente porque se põe no mesmo lugar de opressão pessoas que vivem a transexualidade cotidianamente, travestis e transexuais, ao lado de pessoas que podem ser cisgêneras e que, portanto, vivem a transexualidade apenas por alguns minutos ou horas das suas vidas, tais como drag queens e crossdressers; faço uso desse léxico de maneira estratégica (MOITA LOPES, 2020; VALE DE ALMEIDA, 2009) no trabalho, pois, como veremos no material empírico gerado, não definimos se a pessoa focalizada era mesmo uma travesti, uma mulher transexual, uma pessoa intersexal etc.

O material empírico foi gerado em agosto de 2015, foi primeiramente discutido na minha dissertação de Mestrado² (LIMA-NETO, 2017) e a figura da pessoa utilizada na atividade é esta:

1. Assim como aprendi com a própria autora, neste texto, "na primeira vez que há a citação [direta] de um/a autor/a, transcrevo seu nome completo para a identificação do sexo (gênero) e, consequentemente, para proporcionar maior visibilidade às pesquisadoras e estudiosas" (OLIVEIRA, 2017, p. 14).

2. Certificado de Apresentação de Apreciação Ética da pesquisa: 45632315.6.0000.5083. 


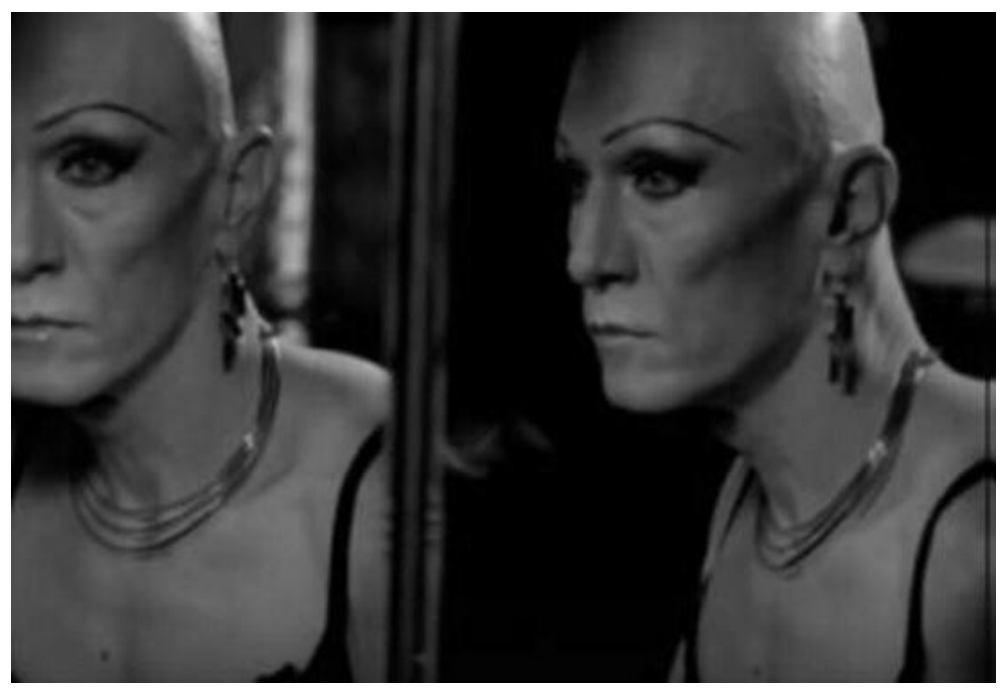

Figura 1. Imagem da pessoa trans utilizada na atividade desenvolvida Fonte: Beautiful (2002).

Antes de avançarmos na rediscussão do material empírico gerado, faz-se importante definir o que entendo por reprodução social e resistência. Como já tive a oportunidade de defender (LIMA-NETO, 2017), mas agora com o auxílio de novas/os teóricas/os, entendo por reprodução social a reiteração, em diversos contextos de enunciação (DERRIDA, 1977; ROCHA, 2013), de ideias e comportamentos begemônicos, que visam tanto à marginalização quanto à manutenção de um estado de marginalidade às/aos participantes dos grupos sociais dominados, a saber, das/os pobres, das/os faveladas/os, das/os negras/os, das/os indígenas, das mulheres e dos homens homoeróticas/os, das mulheres e dos homens em situação de dificuldades social, dentre outras/os (MOITA LOPES, 2006). Essas ideias e comportamentos hegemônicos foram propagados, primeiramente, pelas/os participantes dos grupos sociais dominantes, nomeadamente, das/os ricas/os, das/os que sempre moraram nas regiões mais centralizadas, das/os brancas/os, das/os não indígenas, das/os heterossexuais, das mulheres e dos homens que vivem plenamente etc., e que, posteriormente, foram incorporados nos nossos discursos, por todas/os nós. Nesse sentido, entendo que tais reproduções causam efeitos $^{3}$, mais especificamente efeitos

3. Gostaria de agradecer à Professora Doutora Joana Plaza Pinto, por ter me alertado para o fato de que estava deixando entrever uma visão de linguagem ingênua, não performativa, visão com a qual não me compactuo e não desejo me compactuar, ao não ajustar certas noções no meu texto, dentre elas, a de reprodução social. 
perlocucionários, isto é, consequências que são trazidas ou realizadas através do ato de dizer algo (AUSTIN, 1962), no mundo social, sendo um dos principais deles, nesse caso, a hierarquização das pessoas enquanto seres sociais.

Já por resistência, entendo toda e qualquer ação que se oponha à reiteração das ideias e dos comportamentos hegemônicos, não apenas as que Canagarajah (1993, p. 97-98) consideraria como plenas de uma "ideological clarity and commitment to collective action for social transformation ${ }^{4 \prime}$, mas também as que o autor consideraria como "unclear, ambivalent, and largely passive" (apenas oposição, na sua visão). Portanto, entendo resistência a partir de uma visão foucaultiana (FOUCAULT, 1995; 2014), que vê o conceito como discursivo, relacional, sempre presente onde há poder, não necessariamente repressivo e/ou negativo, mas acional, por assim dizer, já que, segundo o próprio Michel Foucault (1995, p. 243), o que

de fato [...] define uma relação de poder é um modo de ação que não age direta e imediatamente sobre os outros, mas que age sobre sua própria ação. Uma ação sobre a ação, sobre ações eventuais, ou atuais, futuras ou presentes.

4. Opto por não traduzir as citações em língua inglesa neste texto, a fim de valorizar as práticas translíngues (GARCÍA; LI WEI, 2014), as quais são típicas do modo como nos comunicamos desde que o mundo é mundo. Como nos explicam Makoni e Pennycook (2007), as línguas são invenções que fazem parte do grande projeto colonialista/cristão e nacionalista. Obviamente, não nego que essas invenções continuam "alive and kicking", para citar Phillipson (2012 apud KUMARAVADIVELU, 2014), uma vez que os seus efeitos (PENNYCOOK, 2007) podem ser claramente sentidos por nós em várias instâncias das nossas vidas cotidianas. Um desses efeitos, creio eu, é a ideologia linguística de que não podemos entender o que a/o Outra/o fala/ escreve, mesmo quando as línguas possuem muitas semelhanças. Na citação em língua inglesa de Canagarajah (2013) em específico, para citar apenas um exemplo, das 10 palavras presentes, apenas três não são cognatas, ou seja, apenas três não compartilham semelhanças com as suas respectivas equivalências em português, sem falar no fato de que essas três palavras não possuem uma carga semântica muito importante para se compreender o que está ali escrito, haja vista que são apenas preposições. Soma-se a isso, o argumento de que a maioria das pessoas que lerão este texto seja capaz de ler em língua inglesa, uma vez que se destina a um público específico, o qual, por razões socioeconômicas, vê-se obrigado a saber ler nessa língua. Para aquelas/es que, devido às pressões de ideologias linguísticas monolíngues fortíssimas, não se virem capazes de ler em inglês, recorro aos argumentos de Paula (2018, p. 16), que nos lembra que "vivemos em um mundo (e em um país) multicultural, multilíngue, multitecnológico e caracterizado por redes de relações. Assim, não conhecer ou estudar uma língua não mais necessariamente representa um entrave para sua compreensão". Com essa citação, como podemos ver, não nego que possa haver dificuldades por parte de muitas/os leitoras/es de ler em língua inglesa; preferencialmente, quero dizer que há meios (dicionários (eletrônicos), tradutores (eletrônicos), por exemplo) e pessoas que podem auxiliá-las na compreensão das citações escritas nessa língua. Nesse sentido, ao tomar a decisão de não traduzir as citações em inglês neste texto, tomo conscientemente uma decisão política, teoricamente embasada, que visa, principalmente, a valorização e a promoção de leitoras/es cada vez mais multi/translíngues nesse mundo que já o é, que sempre o foi, mas que foi forçado a se esquecer que o é/sempre foi. 
Além das/os autoras/es já citadas/os, apresento as definições de reprodução social e resistência, baseando-me em Kumaravadivelu (2014) e Antonio Gramsci (2004), os quais discutem os conceitos de hegemonia e subalternidade. O primeiro autor, baseado no segundo, explica que hegemonia "is the political, economic, social, cultural, linguistic, or ideological control exercised by one group or nation over another" (p. 11). O segundo, por sua vez, explica que tal controle, ou consenso, é concedido espontaneamente

[...] pelas grandes massas à orientação impressa pelo grupo fundamental dominante à vida social, consenso que nasce "historicamente" do prestígio (e, portanto, da confiança) obtido pelo grupo dominante por causa de sua posição e de sua função no mundo da produção. (p. 21 , grifo no original).

Kumaravadivelu (2014, p. 11, grifos adicionados) explica também, por meio do conceito de subalternidade, o qual, por sua vez, é também um outro conceito gramsciano, que

[...] the hegemonic power structure subordinates the subalterns through an ensemble of political, social, cultural, economic relations that weaken their will to exercise their agency. The process of subordination operates mainly through coercion and cooptation, that is, through the process of marginalization on the part of the dominating forces, and the practice of selfmarginalization on the part of the dominated groups.

Sendo assim, no escopo deste trabalho, considerei os dados gerados como sendo reproduções sociais ou resistências a partir do que foi dito sobre o corpo da pessoa focalizada, durante a atividade pedagógica realizada, a partir das minhas próprias interpretações. Em outras palavras, o que quero dizer é que o parâmetro científico que utilizei para a consideração/distinção dos dados semióticos analisados (se reproduções sociais ou resistências) foi a reiteração de uma ideia ou de um comportamento hegemônico, isto é, de uma ideia ou de um comportamento que visasse, conscientemente ou não, a reconstruir e, assim, a manter o corpo da pessoa enfocada dentro do espaço social de subordinação no qual é permanente e interacionalmente colocada e do qual não the é permitido sair, bem como a ação contradiscursiva a essa ideia, a partir das minhas interpretações do que foi dito, já que, como nos explica Kanavillil Rajagopalan (1990, p. 238), "no fim das contas, o que vale mesmo é a obtenção das condições e não o dizer puro e simples de um conjunto de palavras, ou seja, o fazer [...] não está à mercê do dizer". Isso porque, essencializando de maneira estratégica a pessoa focalizada, ela faz parte e representa um grupo social minorizado, a saber, o grupo social, genericamente identificado no trabalho, mesmo que de maneira reducionista, sabe-se, das pessoas trans. Ademais, soma-se a isso o fato de que vivi as interações analisadas, o que me 
permite interpretar os dados gerados com base nos recursos de quem as viveu em loco (LIMA-NETO, 2017).

O estudo desenvolvido se trata de uma etnografia crítica, pois, com ele, assim como preconizam Mainardes e Marcondes (2011, p. 425), objetivei estabelecer uma relação entre o material empírico gerado e o sistema social mais amplo, além de problematizar "questões relacionadas à reprodução social, desigualdades e formas de opressão dentro e fora do sistema educacional". A turma que participou da atividade era composta por 23 alunas/os (as/os quais nem todas/os participaram da atividade aqui analisada) e por mim, professor da turma.

Para fins de contextualização, na atividade realizada, uma aluna, Allison Hurt, e um aluno, Paulo César ${ }^{5}$, tentam encarnar o corpo de uma pessoa trans e, assim, responder às perguntas feitas pelas/os colegas sobre a vida dessa pessoa, a fim de que 1) praticássemos o conteúdo linguístico que revisávamos em sala, word order in questions; e 2) a fim de que, ao mesmo tempo, tentássemos nos colocar no lugar de uma pessoa cuja identidade se encontrava num espaço não hegemônico de identidade (PESSOA, 2015), de modo a, então, trabalharmos segundo os preceitos de uma educação linguística crítica (PENNYCOOK, 1999, 2001; PESSOA, 2014; PESSOA; HOEZLE, 2017; PESSOA; URZÊDA-FREITAS, 2012a, 2012b). A atividade foi realizada na segunda aula do curso, o que mostra que as construções identitárias analisadas foram produzidas preferencialmente segundo os repertórios sociais prévios das/os participantes. As interações que serão discutidas foram filmadas, posteriormente transcritas e se encontram dispostas em três eventos semióticos.

Como já discutido na minha dissertação,

[f]aço aqui a opção de utilizar o termo "evento semiótico" para me referir ao que ordinariamente chamamos de "excerto", pois, ao me ancorar nos pensamentos de Canagarajah (2013), compartilho da ideia de que o significado é construído através de recursos de todos os tipos (símbolos, ícones e imagens); de que as línguas/linguagens e os recursos semióticos criam significado através de modalidades diferentes, tais como a oral e a visual, e de que os recursos semióticos estão embutidos em ambientes físicos, alinhando participantes, objetos, corpos e contextos para criar significado. (LIMA-NETO, 2017, p. 41, grifos no original).

Por fim, quanto às convenções de transcrição desses eventos semióticos, as estabeleci com base em Bucholtz (2000):

5. Muitos dos nomes das/os participantes do estudo são fictícios e foram escolhidos pelas/os próprias/ os participantes. 


\begin{tabular}{|c|c|}
\hline Símbolos & Significado \\
\hline Sublinhado & ênfase \\
\hline$()$. & pausa de 0.5 segundos ou menos \\
\hline (Número.número) & pausa maior que 0.5 segundos \\
\hline$($ ) & comentário feito por mim para contextualização do evento semiótico \\
\hline$[$ ] $]$ & sobreposição de falas: início e fim \\
\hline$([$ ] $)$ & $\begin{array}{r}\text { transcrição fonética, segundo os, sons da língua inglesa, de palavras } \\
\text { que foram corrigidas por mim durante as interações }\end{array}$ \\
\hline$=$ & latching (encadeamento sem pausa entre os turnos de fala) \\
\hline Itálico & trechos considerados como de reprodução social \\
\hline Negrito & trechos considerados como de resistência \\
\hline$"$ palavras em destaque dentro das transcrições \\
\hline
\end{tabular}

Fonte: elaborado pelo autor com base nas convenções de transcrição de Bucholtz (2000)

\section{DISCUSSÃO TEÓRICO-ANALIITICA ${ }^{6}$}

Todo significado é produzido indexicalmente, defendem Ron Scollon e Suzie Wong Scollon (2003). Mas o que é indexicalidade? Segundo o autor e a autora, indexicalidade é uma "property of language [...] that [...] makes part of its meaning because of where it is in the world" (SCOLLON; SCOLLON, 2003, p. 25). Sendo assim, para o autor e para a autora, o significado de um signo, seja ele qual for, "is produced only through the placement of that sign in the real world in contiguity with other objects in that world".

Similarmente, Branca Falabella Fabrício (2016) também advoga pelo conceito de indexicalidade para que possamos compreender melhor como os significados são (re)produzidos sociointeracionalmente. Segundo a autora, basicamente, o conceito tem a ver com os apontamentos que fazemos ao interagir umas/uns com as/os outras/os. Tais apontamentos, mais do que apenas carregar uma dimensão denotacional, carregam consigo "a non-referential dimension which indicates expectations, sociocultural rituals, and subject positions that are racialized, genderized, sexualized, nationalized, etc.", a qual, "do not [only] 'refer to', but frame interpretation, interfering in processes of perception and meaning-making"

6. Promovo esse tipo de discussão, a fim de, assim, suavizar a separação entre teoria e análise típica não apenas dos estudos linguísticos, mas de todos os estudos de todas as áreas do conhecimento científico. 
(FABRÍCIO, 2016, p. 135). Assim, a seu ver, esse conceito nos ajuda a enxergar os contextos e os referentes

[...] as in-progress environments, and [the] meaning-making [process] as a nomadic event, paradoxically lingering-moving, in which the chance to determine meaning is referenced not to perennial, or authentic, referents, but to texts that point to texts, signs that point to signs[,]

fazendo-nos perceber, enfim, que "there are no essential social meanings, identities, or categories, but rather, perpetual processes of entextualization which, through repetition, generate a sense of stability" (FABRÍCIO, 2016, p. 136).

De acordo com Michael Silverstein (2003, p. 193), por sua vez, mais importante do que o próprio conceito de indexicalidade é o conceito de ordem indexical, o qual, a seu ver, é "necessary to any empirical investigation of the inherently dialectical facts of indexicality". O autor explica que esse conceito "comes in integral, ordinal degrees, that is, first-order indexicality, second-order indexicality, etc." (SILVERSTEIN, 2003, p. 193) e que

[...] any $\mathrm{n}$-th order indexical presupposes that the context in which it is normatively used has a schematization of some particular sort, relative to which we can model the "appropriateness" of its usage in that context. At the same time, there will tend to be a contextual entailment-a "creative" effect or "effectiveness" in context—regularly produced by the use of the n-th order indexical token as a direct (causal) consequence of the degree of (institutionalized) ideological engagement users manifest in respect of the $\mathrm{n}$-th order indexical meaningfulness. (SILVERSTEIN, 2003, p. 193-194, grifos adicionados).

Para ele, é exatamente a ordem indexical que faz com que certos significados consigam um status de essência, pois, ao serem reiteradamente utilizados, os valores culturais (as ideologias) que imbuem os signos são naturalizados nas interações, levando-nos, consequentemente, a fazer uso de uma lógica avaliativa para segmentar o espaço social (SILVERSTEIN, 2003). Um exemplo do processo de essencialização que o autor nos dá está no uso da frase boys will be boys. Ao ser enunciada, as pessoas parecem esquecer ou ignorar o fato de que os garotos são o que são porque eles "learn through licensed or warranted perlocutions of gendering" (SILVERSTEIN, 2003, p. 203), lançando mão, assim, da ideia de uma masculinidade essencial, isto é, de uma essência fundamentada num absoluto cósmico (SILVERTEIN, 2003).

Estabelecendo uma relação de intertexto com as teorizações de Jan Blommaert (2010, p. 34), o que podemos perceber é que a ordem indexical "is a sensitizing concept that should index ('point a finger to') important aspects of power and inequality in the field of semiosis", já que, ao serem carregadas de valores sociais e culturais, as formas semióticas "display traces of power and authority, of 
struggles in which there [are] winners as well as losers, and in which, in general, the group of winners is smaller than the group of losers" (BLOMMAERT, 2010, p. 38).

Esses signos, claro, não se referem apenas aos que poderíamos chamar de linguísticos, mas aos que poderíamos chamar de corporais também (risadas, movimentos corporais, falas sorrateiras etc.). Como nos explica Pinto (em conversa com Fabrício e Moita Lopes, 2020), mais do que pensar o corpo apenas como um conjunto de partes (olhos, boca, ouvidos etc.) que nos permite produzir a linguagem, devemos avançar e pensá-lo também como aquilo que, dos espaços, dos objetos e do próprio corpo, é interpretável, ou seja, como um elemento interpretável que aparece dentro do espaço e do tempo sociocultural e historicamente, isto é, o próprio corpo como um signo.

É exatamente no ponto em que podemos ver o poder operando nas relações entre os signos que o conceito de escala nos é importante para entender o conceito de indexicalidade. Basicamente, ainda segundo Blommaert (2010, p. 33, grifos no original), o conceito de escala serve para identificarmos "the jump from one scale to another". No que se refere às escalas sociolinguísticas propriamente ditas, elas servem para identificarmos o salto do "individual to the collective, the temporally situated to the trans-temporal, the unique to the common, the token to the type, the specific to the general". Na visão do autor, tal conceito nos é importante, porque oferece "a vertical image of space, of a space as stratified and therefore powerinvested", permitindo-nos, consequentemente, ver os fenômenos sociolinguísticos "as a non-unified in relation to a stratified, non-unified image of social space" (BLOMMAERT, 2010, p. 34, grifos no original), isto é, permitindo-nos perceber como as formas semióticas, e consequentemente os seus significados também, são preferidos em certos contextos, em detrimento de outros.

Especificamente sobre isso, Blommaert (2010) nos explica que devemos conceber o poder nesse espaço estratificado como algo que "emanate from real or perceived 'centres', to which people orient when they produce an indexical trajectory in semiosis" (BLOMMAERT, 2010, p. 39, grifo adicionado). Com base nas teorizações de Bakthin (1986), o autor declara que, todas as vezes que nos comunicamos, direcionamo-nos para o que esse autor chama de superdestinatários, isto é,

[...] complexes of norms and perceived appropriateness criteria, in effect the larger social and cultural body of authority into which we insert our immediate practices vis-à-vis our immediate addressee (BLOMMAERT, 2010, p. 39) [,]

os quais, por seu turno, "very often, [...] have names, faces, a reality of their own", já que são representados por pessoas comuns no nosso dia-a-dia, tais como "teachers, 
parents, role models" ou, até mesmo, "the coolest guy in class" (BLOMMAERT, 2010, p. 39).

Isso, por conseguinte, nos leva a asseverar duas coisas: 1) muito mais do que apenas um centro, temos diversos centros a partir dos quais enunciamos em termos comunicativos e sociolinguísticos nas nossas interações, isto é, temos uma policentricidade com relação à questão e é isso que nos permite "follow norms or violate them" (BLOMMAERT, 2010, p. 40) seja por querer, por acidente ou porque somos, por algum motivo, incapazes de nos comportar semioticamente diante de uma determinada situação (BLOMMAERT, 2010); e 2) a conexão entre as escalas é sempre indexical (BLOMMAERT, 2010).

Assim, resumidamente, se o conceito de indexicalidade implica as ideias de pressuposição e acarretamento, fica mais fácil de imaginarmos essas pressuposições como sendo nada mais do que os significados macroescalarmente sedimentados, isto é, como sendo os significados que, devido ao fato de serem exacerbada e rotineiramente utilizados nas nossas microinterações, são posicionados na ordens indexicais mais elevadas do espaço social estratificado, não unificado. Fica mais fácil de imaginarmos também que os acarretamentos nada mais são do que as sedimentações, isto é, do que as ações de sedimentar esses significados, e consequentemente os seus efeitos também, os quais só são posicionados nas escalas macro, se forem constantemente reutilizados nas escalas micro. Em suma, indexicalidade e escala são conceitos que se complementam mutuamente.

Nos eventos semióticos performados durante a realização da atividade de sala de aula que desenvolvi com a imagem da pessoa trans anteriormente mostrada, os conceitos de indexicalidade e escala, juntamente articulados, como acabo de defender nos parágrafos anteriores, nos serão extremamente importantes para compreendermos o movimento de reprodução social e resistência, nos momentos em que construíamos uma identidade à pessoa enfocada, baseando-nos no seu corpo. Partamos ao primeiro evento:

\section{[1]}

1 Professor: [...] So, they (Paulo César e Allison Hurt) are these people (a pessoa trans), ok? [...]. And I want you (o restante da sala) to ask them questions, ok? Aluna $1^{7} \underline{\text { too. }}$. (faço gestos com as mãos, sinalizando para que façam as perguntas). $2 \mathrm{ANI}^{8}$ : What's your name?

3 Paulo César: (.) It's Thomas.

7. Aluna 1 é uma aluna que não consentiu participar da pesquisa.

8. Sigla para Aluna/o Não Identificada/o. 
4 Professor: (.) Aham. (Hellbia pergunta sobre a pronúncia correta do nome da pessoa e eu pronuncio). But... Do you like to be called "Thomas"? How do you like people call you?

5 Allison Hurt: "Thomas" was my birth name and... But I prefer "Claire"?

6 Professor: Aham. So, we have to call you "Claire", not "Thomas"?

7 Allison Hurt: Yes.

8 Professor: Ok. Aham. Questions.

9 Dexter: So, Claire, what's your profession?

10 Paulo César: (.) Profession? (risos) (o.8) I'm a stripper in a... (risos) night shows.

11 Professor: You're stripper in a...

12 Paulo César: In a night shows, I don't know.

13 Professor: Night club.

14 Paulo César: Night club.

15 Professor: Aham.

16 Jeremias: If you like... Looks like a woman. Where your bair (a pessoa está careca na imagem)? [...]

17 Professor: So, where's your hair, Claire? (passeio pela sala olhando para a Aluna 1, incentivando-a a responder a pergunta). (0.14). Where's your hair? (0.17) Hair. Aham. (respondo com uma mímica a uma pergunta feita pela Aluna 1 sobre o significado da palavra "hair").

18 Paulo César: (.) I lost my hair in a... car (['æe.sI.dənt]).

19 Professor: In a car [('æk.si.dənt]). Ok. Ahm. Are you bald? Do you understand bald? Bald is a person who doesn't have hair. He's bald (apontando para a pessoa trans e falando para toda a turma). She is bald. And... But, do you go... Do you leave your house like this? Without any hair? (Paulo César diz que não me entendeu. Então, repito). Do you leave your house without any hair?

20 Paulo César: (.) Yeah.

21 Professor: Like this (do jeito que a pessoa focalizada está na imagem)?

22 Paulo César: Yes.

23 Allison Hurt: (incompreensível) How do you say... =.

24 Professor: $=$ Wig. Peruca? Wig. I use wig.

25 Paulo César: Yes. (Transcrição da atividade do dia 18/08/15).

Basicamente o que podemos ver no evento semiótico 1 é um jogo constante de reproduções sociais e resistências com relação ao corpo da pessoa focalizada e à sua suposta identidade de gênero (LIMA-NETO, 2017). A primeira interação que considero como sendo uma reprodução social acontece na interação 3. Isso porque, mesmo diante de um corpo trans, isto é, mesmo diante de um corpo composto, 
simultaneamente, por índices corporais socialmente considerados como masculinos (ausência de cabelo (longo), maxilar e queixo marcado, ausência de seio) e femininos (brincos (grandes)), colar (elaborado), maquiagem (forte), sobrancelha sintética, sutiã), Paulo César não esperou mais que cinco segundos para atribuir um nome masculino, Thomas, à pessoa focalizada. A escolha do signo Thomas aponta para o significado macroescalarmente sedimentado na ordem indexical de que há nomes próprios masculinos ou femininos porque há, primeiramente, corpos masculinos ou femininos. Segundo essa mesma ordem indexical, ser homem ou ser mulher é uma questão de ter certos atributos físicos socialmente considerados como masculinos ou femininos e não um modo, um estilo de viver a vida, uma performance.

Em contraposição a essa reprodução social, eis que surge a primeira resistência na interação 5. Nela, Allison Hurt, estimulada pela minha pergunta na interação 4, resiste a reprodução do colega, atribuindo à pessoa focalizada um nome feminino: Claire, nome esse que, por sua vez, foi reiterado em todas as outras interações quando queríamos nos referir à pessoa trans em questão não apenas no evento semiótico 1 (Dexter, na interação 9; e o professor, eu, na interação 17), mas em todas as demais interações dos demais eventos semióticos. Essa escolha linguística indica, de maneira indexical, isto é, de maneira implícita, a ideia contra-hegemônica, situada no nível escalar oposto ao da escolha lexical Thomas, discutida no parágrafo anterior, de que ser homem ou ser mulher não tem a ver com atributos físicos que socialmente impomos a essas categorias socialmente criadas de pessoas, mas sim com uma forma de viver a vida, com uma vontade individual de se apresentar de uma maneira específica ao mundo e de querer estar nele dessa forma. Ou seja, ao nos valermos de um nome próprio feminino para construirmos (isso porque referir também é uma ação linguística, ao partirmos de uma visão performativa de linguagem) o corpo focalizado, resistimos à ordem indexical hegemônica no tocante a quais signos, no caso específico da interação, quais nomes próprios, devemos utilizar para formar outros signos: no caso, os corpos que chamamos de masculinos ou femininos. Com a utilização do signo Claire, portanto, propomos modos alternativos de usos linguísticos e, como consequência disso, modos alternativos de (re)construirmos os corpos prototípicos que já conhecemos.

No transcorrer do evento, os índices corporais socialmente posicionados nas escalas macro de significação como femininos ou masculinos, presentes no corpo da pessoa trans, continuaram a servir de gatilho para que reproduzíssemos algumas outras ideias hegemônicas sobre corpo e gênero, bem como para que lhes resistíssemos também. Na interação 16, Jeremias questiona Claire a respeito da sua falta de cabelo (grande), já que, se ela se parecia com uma mulber, ela deveria ter cabelo (grande). 
Em resistência a essa ideia, Paulo César, aluno que, como vimos no parágrafo anterior, reproduziu indexicalmente a ideia hegemônica de que ser homem, e consequente e paradoxalmente a de ser mulher também, é ter apenas certos atributos físicos naquilo que convencionamos a chamar de corpo, criou a história de que a pessoa trans focalizada não tinha cabelo (grande), pois o havia perdido em um acidente de carro. O aluno parece fazer isso após perceber que o tom de tratamento dispensado em sala à pessoa focalizada na atividade não era de reprodução social, mas majoritariamente de resistência, alinhando-se, assim, principalmente, a Allison Hurt, no seu compromisso de desexotizar a pessoa trans focalizada, já que ela, dentre todas/os alunas/os, pode ser considerada como a representante do centro de resistência por excelência, isto é, pode ser considerada como a representante do superdestinário politicamente correto, conclusão à qual podemos chegar diante dos seus atos de fala que, ao invés de inferiorizar, Outrizar, exotizar, marginalizar e minorizar a pessoa enfocada, a valoriza, a humaniza, a normaliza, a centraliza e a eleva socialmente não apenas no evento semiótico 1 , mas nos demais eventos semióticos também, como ainda poderemos ver.

Embora, na minha opinião, a história de que a pessoa trans focalizada tenha perdido seu cabelo num acidente de carro seja um tanto quanto estranha, uma vez que, "normalmente, alguém que sofre um acidente de carro tem de conviver com outras sequelas, não [com] a falta de cabelo" (LIMA-NETO, 2017, p. 70), é interessante vermos o aluno, assim como Allison Hurt, no início da interação, resistir à reprodução social de que pessoas femininas, ou feminilizadas, melhor dizendo, precisam ter cabelo (grande) para serem, de fato, consideradas femininas, pois, assim, ele se distancia do significado densamente sedimentado nas escala macro de significação tanto dos corpos quanto, consequentemente, dos gêneros. As interações 20 e 22 são representativas da sua resistência, já que, nelas, ao insistir que Claire sai de casa sem nenbum cabelo, Paulo César legitima, de maneira indexical o corpo trans e a sua identidade de gênero.

No momento exato da interação, bem como no momento da minha primeira análise do evento semiótico, isto é, sem o auxílio dos conceitos de indexicalidade e escala, pensei que, ao insistir em deixar a pessoa trans focalizada sem cabelo, o aluno estivesse reproduzindo mais uma ideia hegemônica contra ela. Foi isso o que fez com que Allison Hurt e eu, nas interações 23 e 24, criássemos rapidamente a contra-história de que Claire usava uma peruca para sair de casa, história à qual o próprio Paulo César se rendeu, na interação 25. Nesse sentido, Allison Hurt e eu reproduzimos o ideal hegemônico do corpo feminino para com a pessoa trans focalizada, mas isso com vistas a não reproduzirmos o lugar de subalternidade que 
é normalmente relegado às pessoas trans na maioria das culturas ocidentalizadas, uma vez que, como Oliveira (em conversa com Silva, 2020) nos mostra, muitos dos estereótipos que poderíamos julgar como opressivos às mulheres, enquanto sujeitos universais, tais como: meninas têm de usar cor de rosa e brincar de boneca; mulheres têm de se casar com homens etc.; se aplicados a mulheres trans, podem se tornar revolucionários, subversivos.

Similarmente, na interação 19, foram novamente os índices corporais que me levaram a cometer o ato falho de me referir a Claire, usando o pronome pessoal masculino be e não o pronome feminino she. Isso porque, como já defendido, está sedimentado no nível macroescalar que os signos mulber e homem não se tratam de signos, mas de essências corporificadas.

Por fim, considero como última reprodução social do evento semiótico a fala de Paulo César, na interação 10. Nela, o aluno atribui uma profissão relacionada ao sexo, stripper, à pessoa trans focalizada e acha isso jocoso (risos na interação). Isso pode ter acontecido, pois, após Allison Hurt, Dexter e eu termos ditado a principal das regras do jogo interacional: a de que a pessoa em questão era uma pessoa trans, Claire, e não um homem, Thomas; Paulo César aciona o significado sedimentado na escala macro do signo trans e, então, não por acaso, lhe atribui a profissão de stripper, que é totalmente marginalizada, acarretando à pessoa enfocada o estado de subalternidade que the é normalmente relegado. Os risos soltos na interação são apenas o primeiro exemplo de que comportamentos hegemônicos, isto é, signos não linguísticos também oprimem tanto quanto ou até mesmo mais do que os que poderíamos chamar estritamente de linguísticos.

Porém, como já dito, Paulo César, alinha-se a Allison Hurt no seu compromisso de desexotizar a pessoa trans focalizada. Evidências disso poderão ser mais bem visualizadas no evento semiótico 2, a seguir:

[2]

1 Dexter: Why you... Why you choose your profession?

(Omitido trecho de explicação gramatical sobre como estruturar a pergunta "Why did you choose your profession?").

2 Allison Hurt: I choose this because I needed the money and I like to dance and this (incompreensível) make presentation in the night club.

3 Professor: Because you like to dance and...

4 Allison Hurt: Make the presentations.

5 Professor: Aham.

6 Hellbia: Are you happy? Are you happy?

7 Allison Hurt: Yes, now, I'm happy. 
8 Professor: (.) Now you are happy. So, in the past... Were you happy in the past? 9 Allison Hurt: No.

10 Professor: Why? Why weren't you happy in the past?

11 Allison Hurt: Because I... I wasn't what I like to be.

12 Professor: Ah, ok! Questions.

13 ANI: (.) [Do you like...].

14 Dexter: (.) [Do you have...].

$15 \mathrm{ANI}$ : Do you like your profession?

16 Allison Hurt: It's worthy. I like it.

17 Professor: Princess... (chamando as/os alunas/os para fazerem mais perguntas).

18 Hellbia: Are you married?

19 Allison Hurt: Yes, I'm married. I have a husband. (.) He owns the night club.

20 Professor: Nice! Did you understand "He owns the night club"? Owns, the night club is of his, he possesses the night club. Her husband. (.) Questions.

21 Jeremias: Do you have another job? A conventional job?

22 Paulo César: (.) No. (incompreensível) This is a conventional job.

23 Professor: This is a conventional job?

24 (Paulo César balança a cabeça indicando que sim).

25 Dexter: Do you have some illness? (Dexter repete, pois não foi compreendido). Illness.

Do you sick?

26 Professor: Ah! Are you.

27 Dexter: Are you sick?

28 Paulo César: No. I'm not sick.

29 Allison Hurt: I (incompreensível) in the car accident.

30 Hellbia: (.) Are you (incompreensível)?

31 Professor: Ahm. "Você tem um filho?", how do I ask this question?

(As/Os alunas/os interagem até produzir a estrutura correta da pergunta "Você tem um filho?").

32 Hellbia: Do you have any children?

33 Paulo César: No, I don't have any children, but I and my husband ahm... We want to adopt any children.

34 Professor: To adopt a child?

35 Paulo César: Yes, a child.

36 Hellbia: Do you like children? (incompreensível).

37 Paulo César: Yes, I like, but I didn't because my brother have a girl and... And in this (incompreensível). 
38 Professor: And can you take this off (referindo-me à mão do aluno, que tampava sua boca)? Can you take (incompreensível) off? (risos). Your husband has a girl... 39 Paulo César: Não. My brother.

40 Professor: Ah! Your brother.

41 Paulo César: Yes, he has a girl and I love...

42 Professor: And you love her. (Transcrição da atividade do dia 18/08/15).

Nesse evento semiótico, o que podemos perceber, basicamente, é que as reproduções sociais foram dando, cada vez mais, espaço às resistências, à medida que a atividade foi se desenrolando (LIMA-NETO, 2017). Podemos perceber isso no momento em que Allison Hurt tenta normalizar os motivos que levaram a pessoa trans a ser uma stripper nas interações 2 e 16: gostar de dançar e fazer apresentações. A aluna não vincula o sexo à profissão, mesmo tendo enfatizado a questão do dinheiro no início da interação. Podemos perceber isso também no momento em que ela diz que a pessoa focalizada gosta da sua profissão, sem mencionar os pontos negativos que deixariam a sua história menos romântica, na interação 16; no momento em que ela cria a história de que a pessoa trans é casada com o dono do night club onde trabalha, na interação 19 , fala essa que recebe um reforço positivo meu na interação subsequente: Nice!; no momento em que Paulo César diz que a profissão de stripper era uma profissão convencional nas interações 22 e 24; no momento em que o aluno e Allison Hurt despatologizam a falta de cabelo e a magreza do corpo da pessoa focalizada, nas interações 28 e 29; no momento em que Paulo César disse que Claire não tinha filhos, mas de que gostaria de adotar um, juntamente com o seu marido, na interação 33; no momento em que ele cria a história de que ela tem uma boa relação com a sua família, brother e sobrinha, e no momento em que ele diz que ela ama essa sobrinha.

Reside nesse processo de normalização a ideia indexicalmente expressa e macroescalarmente sedimentada do que é ser normal, a saber, não trabalhar com sexo; gostar da profissão que se tem; escolher livremente a profissão que se quer ter na vida; ter um relacionamento estável e aparentemente monogâmico; não ser doente; ter justificações que expliquem uma aparência que escape à aparência do corpo saudável; ter filhas/os; e, finalmente, gostar de crianças. Nesse sentido, novamente, resistimos à colocação da pessoa trans focalizada num lugar social de marginalidade, reproduzindo, no nível microescalar, isto é, nas nossas interações, a ordem indexical hegemônica do signo normalidade, dentro da nossa cultura ocidentalizada.

Portanto, as duas únicas reproduções sociais do segundo evento semiótico são performadas por Dexter, que, nas interações 1 e 25, reproduz, respectivamente, as ideias hegemônicas de que "as pessoas sempre escolhem as profissões que têm, 
[inclusive] as que têm profissões marginalizadas, como a de stripper" (LIMA-NETO, 2017, p. 71, grifo no original) e a de que corpos masculinos homoeróticos, que não têm cabelo, possivelmente adicionado a uma magreza (excessiva), estão doentes (LIMA-NETO, 2017).

Por fim, no evento semiótico 3, mais reproduções sociais e resistências com relação à pessoa trans surgem, mas, agora, tendo o pronome pessoal pelo qual ela deveria ser chamada, se be ou se she, como o centro da discussão:

[3]

1 Linda: (.) What... What time does be (refere-se à pessoa trans) job in the night club?

2 Professor: Is this question correct? Let's analyze? Ahm? Let's analyze?

3 Linda: Ask?

4 Professor: Again. What time...

5 Linda: What time... does be $=$.

6 Allison Hurt: $=$ Does she.

7 Professor: Does be $=$.

8 Allison Hurt: [(corrigindo) $=\underline{\text { She }]}$.

9 Linda: [Job, job].

10 Professor: (paro de escrever no quadro e explico) Yes, it's a she.

11 Linda: She?

12 Professor: Aham. What time does she...

13 Linda: She (rindo de forma constrangida)...

14 Maria Eduarda: Ham? (risos) [She?] (risos e burburinhos).

15 Linda: [Job in the night club?] (risos).

16 Professor: Job in a night club? People, is this question correct? What time, is it correct?

17 Alunas/os: Yes.

18 Professor: Auxiliary?

19 Aluna/os: Yes.

20 Professor: She?

21 Alunas/os: Yes.

22 Professor: No. The question is direct. What time...

23 Fernanda: Does she...

24 Alunas/os: Do you (elas/es se autocorrigem).

25 Professor: Do you $=$.

26 Maria Eduarda: =Job.

27 ANI: Work. 
28 Professor: It would be correct, Linda. Seria correto if the question were about Claire, but the question is to Claire, not about Claire, ok?

29 Linda: Ah, tá!

30 Professor: So, "What time do you job", is it correct?

31 Alunas/os: No.

32 Professor: No.

33 Alunas/os: Work.

34 Professor: What is the difference between "job" and "work" (escrevendo no quadro)?

(Omitido trecho no qual as/os alunas/os diferenciam "job" de "work" e no qual Linda é levada a estruturar a pergunta seguinte).

35 Linda: "What time do you work the night club?"

36 Professor: "In the night club".

37 Linda: "In the night club".

38 Allison Hurt: Ahm...

39 Paulo César: I work... Every day at 8:00.

40 Professor: At 8:00 p.m.? Aham. And do you work all night long?

41 Paulo César: Yes.

42 Professor: And what do you do when you're not working at night?

43 Paulo César: I'm...

44 Allison Hurt: I stay at home, I go to the shopping (incompreensível), I stay with my husband.

45 Paulo César: I (incompreensível) with my (incompreensível).

46 Professor: Ok. Very good! (Transcrição da atividade do dia 18/03/15).

Como já dito, nesse evento semiótico, a reprodução social e a resistência maior giraram em torno de qual pronome pessoal, be ou she, deveríamos utilizar para nos referirmos à pessoa trans focalizada. Ao passo que duas alunas e eu, em diversas interações $(1,5,7,11,13,14$ e 15), reiteramos, através da utilização do pronome pessoal masculino be, e, através de algumas risadas, a ideia hegemônica e, portanto, macroescalarmente sedimentada, disseminada e defendida anteriormente: a de que a pessoa focalizada era um homem devido às suas características físicas e não uma pessoa trans, isto é, uma pessoa que se encontra na fronteira entre os gêneros; Allison Hurt, Fernanda e eu, também em diversas interações (6, 8, 10, 12, 20,21, 23 e 28), portanto no nível micro, resistimos a essa ideia, chamando-a, na grande maioria das vezes, metapragmáticamente, de she, pronome pessoal feminino em inglês. Ao fazermos isso, defendemos, novamente, então, a ideia de que ser feminina/o depende mais dos signos corporais que escolhemos usar nos nossos 
corpos, tais como acessórios, por exemplo, do que dos signos corporais com os quais nascemos, tais como um certo tipo de maxilar e queixo, um certo tipo de peito, ou até mesmo um certo tipo de genitália. Por mais que as nossas genitálias não sejam recorrentemente vistas para que reconstruamos os nossos corpos, nas nossas interações cotidianas, elas são extremamente necessárias para que batizemos os nossos corpos como masculinos ou femininos e é desse batismo do qual decorrem várias das nossas futuras reconstruções identitárias, como nos aclara Judith Butler (1997).

Porém, como podemos ver na interação 44 do evento semiótico, uma outra reprodução social, novamente uma reprodução social resistente, similar àquelas que vimos no evento semiótico 1 e 2, acontece. Nessa iteração, Allison Hurt reproduz novamente o significado macroescalarmente sedimentado de normalidade: no caso, ficar em casa, fazer compras e ficar com o marido (no caso de corpos feminilizados), quando se está de folga. Isso a fim de, dessa forma, resistir às interações e as formas linguísticas que visavam, consciente ou inconscientemente, recriar o estado de marginalidade e subalternidade social que, infelizmente, relegamos às pessoa trans em sociedades como a nossa, as quais, por sua vez, como podemos concluir após essas análises, são, indubitavelmente, transfóbicas.

\section{CONCLUSÕES}

A rediscussão dos eventos semióticos neste artigo me levou a várias conclusões. A primeira delas é a de que os conceitos de indexicalidade e escala podem contribuir muitíssimo para a compreensão do movimento de reprodução social e resistência característico das nossas interações como um todo, e das interações que realizamos nas nossas salas de aula (de língua) em específico, pois eles nos permitem, assim como defendem as/os próprias/os autoras/es aqui citadas/ os, relacionar o micro ao macro, e vice-versa, mostrando-nos como, na verdade, esses dois níveis escalares se constituem mutuamente e como, de fato, a relação entre eles é indexical.

Consequentemente, pude concluir que o estado de subalternidade relegado às/aos membras/os dos grupos sociais marginalizados não é sustentado, na maioria das vezes, por grandes eventos de preconceito (transfobia, no caso deste texto em particular), mas, preferencialmente, por micro, ou nano, se assim desejarmos, interações linguístico-sociais. Na verdade, como nos explica Rocha (2013), a fala, nesse caso, funciona como o prelúdio da tragédia e da dor física, que, por muitas vezes, se concretiza, infelizmente. 
Similarmente, conclui que os conceitos utilizados nos ajudam a compreender como a resistência ao estado de subalternidade e marginalidade também se dá, na maioria das vezes, da mesma forma, ou seja, ajudam-nos a compreender como mudar o mundo (LOPES, BORGES, 2015) depende, muitas das vezes, ou, na maioria delas, mais de ações sutis do que de grandes feitos heroicos.

Conclúi também que o que fiz na primeira análise dos eventos semióticos, na minha dissertação de Mestrado, a saber, afirmar que uma/um interactante reproduz alguma ideia hegemônica ou the resiste devido a alguma das suas identidades, como quando, por exemplo, declarei que Allison Hurt e eu resistimos às ideias hegemônicas feitas à pessoa trans focalizada porque, respectivamente, não nos definíamos em termos de sexualidade durante o período de realização da pesquisa ou porque nos considerávamos como homossexuais, não parece ser um argumento do qual devemos nos valer, haja vista que isso não me impediu de chamar a pessoa focalizada de be em diversos momentos, mesmo que eu me defenda, dizendo que fiz isso apenas inconscientemente. Após a escrita deste texto, na minha opinião, fazer isso é se valer de um essencialismo identitário.

Por fim, concluí que os conceitos de indexicalidade e escala podem nos ajudar a desmontar a ideia hegemônica de que as essencializações e as naturalizações preexistem à linguagem, fazendo-nos enxergar, com mais exatidão, como, de fato, nossas identidades são social e reiteradamente construídas; além de nos fazer compreender que a sala de aula (de língua) é, verdadeiramente, uma zona de contato como nos sugere Mary Louise Pratt (1991, p.34), uma vez que é um espaço social "where cultures meet, cloth, and grapple with each other, often in contexts of highly asymmetrical relations of power".

\section{REFERÊNCIAS}

AUSTIN, John Langshaw. (1962). How to do things with words: The William James Lectures Delivered at Harvard University in 1955. Cambridge: Harvard University Press.

BEAUTIFUL. (2002). Em aberto. EUA, 3:58. Disponível em: https://www.youtube.com/ watch?v=eAfyFTzZDMM. Acesso em: 20 set. 2019.

BENTO, Berenice. (2014). Nome social para pessoas trans: cidadania precária e gambiarra legal. Contemporânea, São Carlos, v. 4, no. 1, p. 165-182.

BLOMMAERT, Jan. (2010). The Sociolinguistics of Globalization. Cambridge: University Press. 
BUCHOLTZ, Mary. (2000). The politics of transcription. Journal of Pragmatics, v. 32, p. 1439-1465.

BUTLER, Judith. (1997). Excitable speech: a politics of the performative. New York: Routledge.

CANAGARAJAH, Suresh. (1993). Critical ethnography of a Sri Lankan classroom: Ambiguities in student opposition to reproduction through ESOL. TESOL Quarterly, v. 27, p. 601-626.

CANAGARAJAH, Suresh. (2013). Translingual practice: global Englishes and cosmopolitan relations. New York/London: Routledge.

DERRIDA, Jacque. ([1976] 1977). Limited Inc. Evanston: Northwertern University Press.

FABRÍCIO, Branca Falabella. (2016). Mobility and discourse circulation in the contemporary world: the turn of the referential screw. Revista da Anpoll, v. 1, no. 40, p. 129-140.

FABRÍCIO, Branca Falabella; MOITA LOPES, Luiz Paulo da. PINTO, Joana Plaza. (2020). $\mathrm{O}$ que a linguagem tem a ver com o corpo? Rio de Janeiro/Goiânia. Em aberto. Disponível em: <https://www.youtube.com/watch?v=XoyU9ICxAvc $>$. Acesso em: 06 maio 2020.

FOUCAULT, Michel. (1995). O sujeito e o poder. In: DREYFUS, Hubert; RABINOW, Paul. Michel Foucault, uma trajetória filosófica: (para além do estruturalismo e da bermenêtica). Trad. Vera Porto Carrero. Rio de Janeiro: Forense Universitária, p. 231-249.

FOUCAULT, Michel. (2014). O sujeito e o poder. In: FOUCAULT, Michel. Genealogia da Ética, subjetividade e sexualidade. Trad. Elisa Monteiro e Inês Autran Dourado Barbosa. Rio de Janeiro: Forense Universitária, p. 118-140.

GARCÍA, Ofelia; LI WEI. (2014). Translanguaging. New York/London: Palgrave Pivot.

GRAMSCI, Antonio. (2004) Os intelectuais. O principio educativo. In: GRAMSCI, Antonio. Cadernos do cárcere. Trad. Carlos Nelson Coutinho. Rio de Janeiro: Civilização Brasileira, v. 2, p. 11-192.

KUMARAVADIVELU, Bala. (2014). The decolonial option in English teaching: can the subaltern act? TESOL Quarterly, p. 1-20.

LIMA-NETO, Luiz Martins de. (2017). Ensino crítico de línguas: reprodução social e resistência em uma sala de aula de língua inglesa. Dissertação (Mestrado). Brasil: Universidade Federal de Goiás. 
LOPES, Alice Casimiro; BORGES, Veronica. (2017). Formação docente, um projeto impossível. Caderno de Pesquisa [online], v. 45, no. 157, p. 486-507.

MAINARDES, Jefferson; MARCONDES, Maria Inês. (2011). Reflexões sobre a etnografia crítica e suas implicações para a pesquisa em educação. Educ. Real, v. 36, no. 2, p. 425-446.

MAKONI, Sinfree; PENNYCOOK, Alastair. (2007) (Eds). Desinventing and Reconstituting Languages. Clevedon: Multilingual Matters.

MOITA LOPES, Luiz Paulo da. (2006). Linguística Aplicada e vida contemporânea: problematização dos construtos que têm orientado a pesquisa. In: MOITA LOPES, Luiz Paulo da. (Org). Por uma Linguística Aplicada Indisciplinar. São Paulo: Parábola Editorial, p. 85-107.

MOITA LOPES, Luiz Paulo da. (2020). Teorias queer, performatividade e ideologias linguísticas. Em aberto. Rio de Janeiro. Disponível em: https://www.youtube.com/ watch?v=KLW1SY5FD6g. Acesso: 26 jun. 2020.

OLIVEIRA, Megg Rayara Gomes de. (2017) O diabo em forma de gente: (r)existência de gays afeminados, viados e bichas pretas na educação. Tese (Doutorado). Brasil: Universidade Federal do Paraná.

OLIVEIRA, Megg Rayara Gomes; SILVA, Clodoaldo Ferreira Fernandes da. (2020). Transfeminismo, educação e direito à existência. Em aberto. Anápolis/Curitiba. Disponível em: https:/www.instagram.com/tv/CBCCNgIDWnE/?igshid=1h25f5yhx1o70. Acesso: 25 jun. 2020.

PAULA, Charlene Stephany Marilyn Meneses. (2018). Relações de poder, tensões, conflitos e resistências: um estudo etnográfico com um grupo de professoras/es de inglês de um curso de formação continuada. Tese (Doutorado). Brasil: Universidade Federal de Goiás.

PESSOA, Rosane Rocha. (2014). A critical approach to the teaching of English: pedagogical and identitiy engagement. Revista Brasileira de Linguística Aplicada, v. 14, no. 2, p. 353-372.

PESSOA, Rosane Rocha. (2015). Corpos em cena na formação crítica docente. In: Caderno de resumos do International Congress of Applied Linguistics. Brasília: UNB/UEL, p. 14-15.

PESSOA, Rosane Rocha; HOEZLE, Maria José. (2017). Ensino de línguas como palco de política linguística: mobilização de repertórios sobre gênero. Trabalbos em Linguística Aplicada, v. 56, no. 3, p. 781-800. 
PESSOA, Rosane Rocha; URZÊDA-FREITAS, Marco Túlio de. (2012a). Challenges in critical language teaching. TESOL Quarterly, v. 46, p. 753-776.

PESSOA, Rosane Rocha; URZÊDA-FREITAS, Marco Túlio de. (2012b). Ensino crítico de línguas estrangeiras. In: FIGUEIREDO, Francisco Quaresma. (Org.). Formação de professores de línguas estrangeiras: princípios e práticas. Goiânia: Editora UFG, p. 57-80.

PENNYCOOK, Alastair. (2001). Critical Applied Linguistics: a critical introduction. New Jersey: Lawrence Erlbaum Associates.

PENNYCOOK, Alastair. (1999). Introduction: critical approaches to TESOL. TESOL Quarterly, v. 33, no. 3, 329-348.

PENNYCOOK, Alastair. (2007). The Myth of English as an International Language. In: MAKONI, Sinfree; PENNYCOOK, Alastair. (Eds). Desinventing and Reconstituting Languages. Clevedon: Multilingual Matters, p. 90-115.

PRATT, Mary Louise. (1991). Arts of contact zone. Profession, p. 33-40.

RAJAGOPALAN, Kanavillil. (1990). Dos dizeres diversos em torno do fazer. D.E.L.T.A., v. 6, no. 2, 223-254.

ROCHA, Luciana Lins. (2013). Teoriaqueerea saladeaulade inglêsnaescolapública: performatividade, indexicalidade e estilização. Tese (Doutorado). Brasil: Universidade Federal do Rio de Janeiro.

SCOLLON, Ron; SCOLLON, Suzie Wong. (2003). Discourses in place. Language in the material world. London. New York: Routledge.

SILVERSTEIN, Michael. (2003). Indexical order and the dialectics of sociolinguistic life. Language \& Communication, n. 23, p. 193-229.

VALE DE ALMEIDA, Miguel. (2009). Ser mas não ser, eis a questão. O problema persistente do essencialismo estratégico. Working papers CRIA 1, p. 1-9.

Recebido: 24/7/2019

Aceito: 23/6/2020

Publicado: 4/8/2020 